\section{A (re)conciliação com a tradição}

Francisco WEFFORT. Formação do pensamento político brasileiro. São Paulo, Ática, 2006. 360 páginas.

\section{Bernardo Ricupero}

Formação do pensamento político brasileiro é um ensaio. Faz parte, portanto, da tradição de livros desse gênero que tratam de grandes temas brasileiros. Não deixa até de haver uma certa ironia o fato de Weffort, que teve um papel importante na afirmação das ciências sociais brasileiras, ter-se voltado à forma literária, que parecia ter sido sepultada definitivamente pelas próprias ciências sociais. Mas, mesmo antes, aquele que mais contribuiu para que se impusesse o padrão científico de trabalho intelectual nas ciências sociais brasileiras, Florestan Fernandes (1987), também sentiu a necessidade de revisitar o gênero que anteriormente havia predominado no pensamento social brasileiro, o que está expresso, até de forma tensa, no subtítulo de seu último grande trabalho: A revolução burguesa no Brasil: um ensaio de interpretação sociológica.

Trajetórias como essas indicam a consolidação das ciências sociais no Brasil. É significativo que, quando não mais se questiona o seu lugar na vida intelectual brasileira, alguns dos protagonistas do seu processo de institucionalização sintamse à vontade para se aventurar em outros gêneros que não a monografia acadêmica. O ensaísmo, em particular, tem a vantagem de ultrapassar possíveis limitações do trabalho universitário, especialmente a excessiva especialização.

Mas Weffort não muda apenas de gênero, também seu enfoque analítico não é mais o mesmo de trabalhos anteriores. Antes, foi um autor bastante identificado com o marxismo, o que se percebe na sua crítica à teoria da dependência, desenvolvida com base principalmente no argumento de que ela não resolve "o problema de como combinar a dependência externa (âmbito das relações entre as Nações latino-americanas e os 'países centrais') e a dependência interna (âmbito das relações de produção e de classe no interior das Nações latino- americanas)" (Weffort, 1989, p. 169). Numa orientação diferente, a atual postura do autor de Formação do pensamento político brasileiro é resolutamente culturalista. Apoiado, em grande parte, em Richard Morse (1988), ressalta especialmente o peso, no pensamento político e na própria experiência humana no Brasil, da opção cultural tomada por ibéricos na decisiva conjuntura histórica estabelecida entre os séculos XII e XVII.

Assim, para entender o pensamento político brasileiro, é levado a retornar ao Portugal dos descobrimentos, na sua ambígua relação com a Idade Média e a Idade Moderna. De forma bastante sugestiva, chega a defender "que o ponto de partida do pensamento brasileiro se acha no século XV, com o Infante D. Henrique, e não no XVI, com Maquiavel, ou no XVII, com John Locke" (p. 10). Essa démarche também faz com que pratique uma história das idéias que não se limita apenas a autores, mas também leva em conta a história política e social.

Como é natural, a perspectiva culturalista de Formação do pensamento político brasileiro traz vantagens e desvantagens. Ela se revela especialmente adequada para captar traços presentes na mentalidade que orientou a colonização brasileira, por exemplo, um certo medievalismo dos bandeirantes. Por outro lado, não deixa de subestimar alguns aspectos materiais mais modernos, como a orientação mercantil da colonização.

O culturalismo de Weffort também se percebe no tratamento dos autores, em particular, Gilberto Freyre. Considera que sua análise teria a vantagem de, a partir da cultura, tratar da economia. Dessa maneira, o sociólogo pernambucano seria capaz de não reduzir o escravo à coisa, mas reconhecer sua humanidade. Não é, entretanto, dada muita atenção à limitação decorrente da explicação de Casa-grande E senzala se deter nos muros do engenho. Obscurece-se, dessa maneira, a percepção de que aquilo que está por trás da produção no latifúndio e, conseqüentemente, da formação da própria família patriarcal brasileira, é o mercado externo, onde se realiza o que Caio Prado Jr. chamou de "sentido da colonização".

É bem possível que a passagem de uma postura mais materialista para uma atitude mais culturalista se deva, em grande parte, ao período em que o autor de Formação do pensamento político 
brasileiro esteve à frente do Ministério da Cultura (Minc). Caricaturalmente, talvez se pudesse sugerir que o marxista, que ajudou a fundar o Partido dos Trabalhadores (PT), se converteu no culutralista ministro do governo Fernando Henrique Cardoso. O que essa caricatura esquece, contudo, é que no intervalo entre a Secretaria Geral do PT e o Minc, Weffort escreveu dois ensaios - Por que democracia? e Qual democracia? - que tiveram um importante papel na conversão da esquerda brasileira à democracia.

$\mathrm{Na}$ verdade, como outros intelectuais latinoamericanos de esquerda, Weffort foi profundamente marcado pela experiência do regime autoritário, o que contribuiu para que, como sintetizou Carlos Nélson Coutinho (1984), passassem a encarar a democracia como um valor universal. No caso em questão, essa sensibilidade para entender a democracia e suas práticas além de simples arranjos institucionais, como "formas de algum conteúdo" (Weffort, 1992, p. 99), não deve ter deixado de contribuir para uma posterior abertura diante da cultura.

Em termos ainda mais polêmicos, talvez se pudesse tomar a trajetória de Weffort como prova da pretensa convergência - reiteradamente afirmada nos últimos tempos - entre o PT e o Partido da Social-Democracia Brasileira (PSDB). Nessa perspectiva, o caminho político do principal crítico do populismo possivelmente fosse tomado como indicação, especialmente forte, da proximidade entre esses dois partidos "paulistas". Afinal, as presidências Fernando Henrique Cardoso e Luis Inácio Lula da Silva teriam, como principal realização, o programa negativo de demolição do "legado da era Vargas". Em outras palavras, PT e PSDB procurariam expandir, de São Paulo para o restante do país, a representação classista, implícita ou explicitamente defendida pela crítica do populismo.

No entanto, em sentido oposto, o mais interessante em Formação do pensamento político brasileiro é como se busca uma conciliação com a história brasileira. De maneira significativa, a resposta à pergunta de Raymundo Faoro (1984) "existe um pensamento político brasileiro?" - é positiva. De certa forma, o próprio aparecimento de um livro que serve de introdução ao pensamento político brasileiro, inspirado em outro, também organizado por Weffort, Os clássicos da política (1989), dedicado a um tema mais evidente, o pensamento político europeu, é indicação da existência desse pensamento.

A resposta positiva à questão da existência de um pensamento político brasileiro não deixa de ser, porém, difícil, até porque a formação do pensamento político brasileiro não vislumbra, pelo menos no período analisado por Weffort, a autonomização de seu campo de atuação. Isso é diferente inclusive do outro processo brasileiro clássico de formação, o da literatura, que, segundo Antonio Candido (1993), criou, no final do século XIX, um sistema literário. Ao contrário, a grande realização dos ensaístas, dos anos de 1920 e 1930, estaria precisamente em revelar a ligação do Estado com a sociedade brasileira.

Aparece aí o grande tema de Formação do pensamento político brasileiro, a saber, o povo como assunto tratado por intelectuais. A referência ao povo como tema leva o livro a empreender um longo caminho, que começa, já na Colônia, com a discussão sobre a humanidade dos povos conquistados, realizada pelos jesuítas Manuel da Nóbrega e Antonio Vieira; passa pela percepção, por parte de José Bonifácio, logo depois da Independência, de que não se poderia ter verdadeira nação num país baseado na escravidão; ganha forma lapidar na interpretação de Joaquim Nabuco, durante a crise do Império, de que se precisa pôr fim ao trabalho servil, "fenômeno social total", para se criar algo como um povo; vai mais longe com a indicação de Euclides da Cunha, no contexto posterior à proclamação da República, de que o verdadeiro Brasil é o dos sertões e não o do litoral; e abre novas perspectivas na exploração, empreendida pelos ensaístas dos anos de 1930, Gilberto Freyre, Sérgio Buarque de Holanda e Caio Prado Jr., de quem é o povo brasileiro.

Por outro lado, o outro assunto importante de Formação do pensamento político brasileiro, o Estado, teria uma história mais recente no país. Weffort argumenta até, contra uma influente linha de interpretação do Brasil, que a formação do Estado no país seria tardia, coincidindo com a vinda, em 1808, da família real portuguesa para o Rio de Janeiro.

Não é, entretanto, difícil perceber que os dois temas privilegiados neste ensaio se confun- 
dem, a atenção ao povo sendo, desde a Colônia, motivada, em grande parte, por considerações de "razão de Estado". Tal perspectiva é particularmente forte para o importante ministro de Pedro I, José Bonifácio, e para o influente consultor jurídico do Ministério do Trabalho de Getúlio Vargas, Oliveira Vianna.

Mas, como nota o próprio Weffort, se é mais fácil "saber quando começa a formação do pensamento social e político brasileiro, mais duvidoso é decidir quando essa formação se completa" ( $p$. 11). Na quase impossibilidade de precisar quando isso ocorre, o autor decide privilegiar o Brasil rural, encerrando sua análise nos anos de 1950. No entanto, não explica inteiramente por que o Instituto Superior de Estudos Brasileiros (Iseb), representado especialmente por Hélio Jaguaribe, é contemplado no livro, mas não a USP, de Florestan Fernandes.

Mesmo que os estudos sobre desenvolvimento realizados na USP tenham se dado sobretudo na década de 1960 e reflitam uma profissionalização do trabalho intelectual, em que professores universitários tomam o lugar do que se poderia chamar de intelectuais diletantes, não deixou de haver interlocução entre as duas instituições. Os encontros e desencontros entre Iseb e USP podem até serem tomados como marcos importantes de um novo momento no processo de formação do pensamento social e político brasileiro: o da emergência do Brasil urbano.

A exclusão da escola onde Weffort se formou não é, todavia, inocente. O motivo dessa supressão parece-me estar na sua resposta à pergunta de Faoro sobre a existência de um pensamento político brasileiro. Isto é, por trás da resposta positiva à questão está uma certa valorização da tradição à qual esse pensamento político está vinculado. Se ainda é possível relacionar essa tradição com o Iseb, mais difícil é fazer o mesmo com as ciências sociais da USP, que se estabeleceram a partir da crítica ao pensamento social e político anteriormente dominante no Brasil.

Em outras palavras, Formação do pensamento político brasileiro faz parte de uma busca, mais do que centenária, de resposta à questão: quem somos?. Mais importante, oferece uma resposta otimista à pergunta, que só tem se tornado mais comum ultimamente. Mais: a (re)conciliação com a história brasileira expressa no livro talvez possa até ser tomada como sinal de crescente confiança no país. Ironicamente, porém, Weffort, ao assumir essa postura, afasta-se da tradição na qual se formou...

\section{Bibliografia}

CANDIDO, Antonio. (1993), Formação da literatura brasileira. Belo Horizonte, Itatiaia.

COUTINHO, Carlos Nelson. (1984), A democracia como valor universal e outros ensaios. Rio de Janeiro, Salamandra.

FAORO, Raymundo. (1984), Existe um pensamento político brasileiro? São Paulo, Ática.

FERNANDES, Florestan. (1987), A revolução burguesa no Brasil: um ensaio de interpretação sociológica. Rio de Janeiro, Guanabara.

MORSE, Richard. (1988), O espelho de Próspero. Trad. Paulo Neves. São Paulo, Companhia das Letras.

WEFFORT, Francisco. (1980), O populismo na politica brasileira. Rio de Janeiro, Paz e Terra.

(1984), Por que democracia? São Paulo, Brasiliense.

(org.). (1989), Os clássicos da política. São Paulo, Ática.

(1992), Qual democracia? São Paulo, Companhia das Letras.

\section{BERNARDO RICUPERO é professor do Departamento de Ciência Política da Faculdade de Filosofia, Letras e Ciências Humanas da Universidade de São Paulo (USP).}

